\title{
Factors Affecting Tourist Satisfaction: An Empirical Study in the Northern Part of Thailand
}

\author{
Suthathip Suanmali ${ }^{1}$ \\ ${ }^{1}$ School of Management Technology, Sirindhorn International Institute of Technology, Thammasat \\ University, Pathumthani 12000, Thailand
}

\begin{abstract}
In 2015, the ASEAN Economics Community (AEC) will be fully implemented, and, to pave the way for Thailand to be the tourism hub of Southeast Asia, it is important to study factors affecting tourist satisfaction. The emphasis of this study is on a northern province in Thailand, Chiang Mai, where there are many natural and cultural attractions. The significant factors are identified using statistical techniques. The data is obtained from a satisfaction survey as it was developed and distributed randomly to foreign tourists who visit Chiang Mai. The quantitative data is then analyzed using factor analysis and multiple regression analysis to identify significant factors. The result indicates that the most significant factor affecting the overall satisfaction is the cost of staying, and other significant factors are hospitality, attractions and accessibility, and infrastructure. In addition, policy recommendations are presented in the paper.
\end{abstract}

\section{Introduction}

Thailand is a destination with many iconic tourist attractions, such as mountains, islands, culture and traditions, architectures, the way of life, and foods. The tourism industry plays a vital role as an industry of Thailand. It is extremely essential to Thailand's economy. According to the statistical data from the Ministry of Tourism and Sports shows that the revenue received from the tourism industry in 2012 was $983,928.36$ million Baht, increased by $26.76 \%$ from 2011 . The number of international tourist arrivals in Thailand in 2012 was 22,353,903 people. The value of the tourism industry has increased by $16.24 \%$ from 2011 . The average expenditure is $4,392.81$ Baht person per day, with revenue of 983,928.36 million Baht. The average growth rate for the years 1987-2012 has increased by $7.72 \%$.

In 2015, the ASEAN Economic Community will be implemented. This will strongly affect Thailand's tourism industry. Dr. Suthawan Chirapanda, Principle of School of Business, University of the Thai Chamber of Commerce has forecasted the number of tourists visiting Thailand at around twenty million people and forecasted that Thailand will rank as the second country in Asia that tourists choose to visit. This is also due to the fact that Thai people radiate warmth like no other.

The international community has long regarded Thais as people whom are friendly, welcoming, and good in services. In terms of liberal arts, Thailand is also considered as a forerunner in attractiveness because of the exoticness in designs and patterns. There are plenty of tourist attractions, such as Chiang Mai, Phuket, Krabi, Pattaya, etc. The strength of Thailand is further augmented due to its geographical location, since it is the center of ASEAN. Provinces that contribute highly to the tourism industry's income for Thailand are Phuket, Bangkok, Krabi, Chonburi, and Chiang Mai. 
According to the 2013 Travelers' Choice Destinations award, Chiang Mai (Thailand) is ranked in 24th place in the World and in 5th place in Asia. Chiang Mai is a cultural and natural wonderland with ethnic diversity, a multitude of attractions, and the welcoming hospitality of Thailand. Chiang Mai is the largest and most culturally significant city in northern Thailand and is one of the oldest cities in Thailand and has a small-town, old-world attitude completely different from the hustle and bustle of Bangkok. Chiang Mai is a place where both backpackers and luxury tourists can enjoy the ultimate Thailand holiday.

To conclude, the AEC will be implemented shortly and Thailand is aimed to be the hub of tourism. It is important to study factors affecting tourist satisfaction. The emphasis of this study is on Chiang Mai, on nature and entertainment attractions. A satisfaction survey is developed and distributed randomly to tourists who visit Chiang Mai.

\section{Literature Review}

Leading researchers have recognized the important of tourism products: "Misunderstanding of the tourism product is often a constraint in a smoothly functioning tourism system". Tourism product development includes information services, transportations, accommodations, and attraction [1].

The tourism product is described as a series of determinants from variable destinations, which produce an output for tourists. The model consists of a hierarchy of five elements: the physical plant, service, hospitality, freedom of choice, and involvement. As described in this research, the physical plant is the core of the tourism product, which includes the natural resources, fixed properties (such as accommodations), accessibility, acceptable environmental quality, good weather, and appropriate numbers of other tourists [2]. The input of services makes the physical plant useful for tourists, and refers to the performance of specific tasks designed to meet the needs and wants of tourists. Hospitality is the attitude and style in which those specific tasks are performed, for example, a warm and friendly smile by local residents welcoming new arriving tourists. The latter two elements of the model directly involve the tourist as part of the product, which seems logical if tourism is to be considered as an experience. Freedom of choice means that the tourist is entitled to have choices and opinions in order for the experience to be satisfactory. The encapsulating shell of the tourism product is involvement. Successful participation in the tourism product hinges on an acceptable physical plant, good service, hospitality, and freedom of choice. Discomfort with an element will hinder tourist involvement with the tourism product, consequently limiting the quality of the tourism experience. A positive experience with all five elements ensures quality and a satisfying tourism product.

In addition, the research on marketing in travel and tourism. There are five sectors in the in the overall product, which are Hospitality sector, Attractions and events sector, Transportation sector, Travel organizers' and intermediaries' sector, and Destination organization sector [3]. Hospitality is an expression of welcome by local residents to tourists arriving in their community (i.e. hotels, guest houses, apartments, and condominiums). The attraction and event sector can be defined as theme parks, museums and galleries, national parks, heritage sites and centers, and festival and events. The transportation sector includes airlines, shipping lines, railways, bus operators, and car rental operators. Travel organizers and intermediaries sector contains travel e-mediaries, tour operators, tour wholesalers, retail travel agents, and conference organizers. Destination organization sector consists of National tourist offices (NTOs), Destination marketing organizations (DMOs), regional tourist offices, and tourist associations.

Furthermore, the formulation of the components of tourism products is Attractions, Accessibility, Amenities, and Networking. An attraction is a place where attract tourists such as natural, cultural or man-made (festivals or performing arts). Accessibility is the ease of obtaining or achieving organizational goals such as tourism with travel agents. Amenities are facilities for tourists to obtain pleasure. In this case, amenities can be accommodation, cleanliness, and hospitality. Networking is the cooperation by local, national, or international organizations to produce tourism products [4-5].

Customer satisfaction is essential to any business preposition and the same can be said for tourism products. The essence for the success of Chiang Mai tourism industry is definitely tourist satisfaction. 
Tourist satisfaction is important for successful destination marketing because it influences the choice of destination, the consumption of products and services, and the decision to return. Satisfaction is basically the comparison of the customer's expectation before and after consumption. Tourist satisfaction is the difference between tourist's expectations and the actual perceived value [6]. It is important to identify and measure consumer satisfaction with each attribute of the destination because satisfaction or dissatisfaction with one of the attributes leads to satisfaction or dissatisfaction with the overall destination [7-8]. To conclude, satisfied tourists not only will revisit the place, but also will recommend it to others. Besides, increasing the level of satisfaction will reduce the number of tourists' complaints. On the other hand, tourist satisfaction will not be achieved unless the tourists feel that the quality received is greater than the money paid. So, the measurement of overall satisfaction with service quality is an important point of our study. Based on our review on literatures and the characteristics of Chiang Mai, there are six attributes related to this study. The summary of the attributes and their definitions are summarized in Table 1. In addition, the comparison of attributes used in this study and other studies is shown in Table 2.

Table 1. Summary of Chiang Mai Tourism Product

\begin{tabular}{|c|c|c|}
\hline Indicator & Item & Definition \\
\hline Hospitality & $\begin{array}{l}\text { Tangible } \\
\text { Intangible }\end{array}$ & $\begin{array}{l}\text { The tangible and intangible elements affect } \\
\text { tourists' satisfaction: for example, variety of food } \\
\text { or warm and welcoming atmosphere. }\end{array}$ \\
\hline Attraction & $\begin{array}{l}\text { Cultural } \\
\text { Natural } \\
\text { Recreation and Activities }\end{array}$ & $\begin{array}{l}\text { An attraction refers to a place that appeals to } \\
\text { tourists that visit Chiang Mai. An attraction can } \\
\text { be attractive in many ways. For example, } \\
\text { photographers are able to take photographs of } \\
\text { panoramic scenery in Chiang Mai. }\end{array}$ \\
\hline Accessibility & $\begin{array}{l}\text { Transportation } \\
\text { Basic Medical - } \\
\text { Treatments/Hospital } \\
\text { Authorities }\end{array}$ & $\begin{array}{l}\text { Accessibility is defined by the ability to provide } \\
\text { appropriate visitor access into a destination, and } \\
\text { travel throughout the destination. }\end{array}$ \\
\hline Infrastructure & $\begin{array}{l}\text { Water supply } \\
\text { Electricity } \\
\text { Communication } \\
\text { Public lavatory } \\
\text { Safety facilities }\end{array}$ & $\begin{array}{l}\text { Infrastructure is the basic physical needs of the } \\
\text { city, for example, transportation, communication, } \\
\text { sewage, water, and electricity. Infrastructure } \\
\text { projects may be funded publicly or privately. }\end{array}$ \\
\hline Environment & $\begin{array}{l}\text { Climate condition } \\
\text { Air quality } \\
\text { Noise } \\
\text { Natural resources } \\
\text { Cleanliness } \\
\text { Personal safety and security }\end{array}$ & $\begin{array}{l}\text { Environment can be defined as the surroundings, } \\
\text { which includes climate conditions, and } \\
\text { environmental conditions such as air quality, } \\
\text { cleanliness, and feelings towards the destination. }\end{array}$ \\
\hline Cost & $\begin{array}{l}\text { Cost of Accommodation } \\
\text { Cost of Transportation within } \\
\text { Chiang Mai } \\
\text { Cost of Food and Beverages } \\
\text { Other Expenses }\end{array}$ & $\begin{array}{l}\text { The expenses that will be taken into account by } \\
\text { tourists while staying in Chiang Mai. }\end{array}$ \\
\hline
\end{tabular}




\section{Methodology}

\subsection{Method of Approach and Data Collection}

Two research methods are employed in this study. One is documentary research from literature surveys, journals, articles, and previous research works. These data are collected from research published in credible international journals.

Table 2. Comparison of Main Sectors

\begin{tabular}{|l|c|c|c|}
\hline \multicolumn{1}{|c|}{ Main Sector } & $\begin{array}{c}\text { The Impact of Service } \\
\text { Quality on Tourist } \\
\text { Satisfaction in Jerash }\end{array}$ & The Tourism Product & $\begin{array}{c}\text { Factors Affecting } \\
\text { Tourists Satisfaction: A } \\
\text { Case Study in Chiang } \\
\text { Mai }\end{array}$ \\
\hline Hospitality & $\checkmark$ & $\checkmark$ & $\checkmark$ \\
\hline Attraction and Event & $\checkmark$ & $\checkmark$ & $\checkmark$ \\
\hline Accessibility & $\checkmark$ & $\checkmark$ & $\checkmark$ \\
\hline Infrastructure & & $\checkmark$ & $\checkmark$ \\
\hline Environment & & & $\checkmark$ \\
\hline Cost of Staying & & & $\checkmark$ \\
\hline
\end{tabular}

Second is survey research. Surveys are done by means of questionnaire surveys for only foreign tourists who visit Chiang Mai during the time of research. The survey is conducted in such a way that we hand out questionnaires to tourists for them to complete. This takes place at different places of attractions such as temples, heritage sites, and natural attractions. Simultaneously, interviews are administered to business owners in the tourism industries, and travel agencies. Topics addressed are the effect of AEC on Chiang Mai's tourist sector, the interviewee's point of view on the future of Chiang Mai, and the interviewee's point of view on determinants influencing the tourism industry of Chiang Mai overall.

\subsubsection{Population and Sample}

The population is foreign tourists that visited Chiang Mai in the year 2013, and the sample is foreign tourists who visit Chiang Mai that are selected randomly. Specific groups of samples are identified from the current group of tourists. The Yamane sampling technique is utilized.

\subsubsection{Materials}

Instruments used to collect and record data for this study are open-ended interview questions and survey questionnaires (closed questionnaires, 5-point Likert scale, and open-ended questions for instance suggestions and recommendations). Survey questionnaires attempt to address the overall satisfaction of tourism is Chiang Mai, for example, hospitality - variety of food and beverage in Chiang Mai, attraction - varieties of natural such as national parks and trekking, accessibility availability of information and document about Chiang Mai (map and traffic sign), Infrastructure local transportation service, Environment - overall cleanliness of Chiang Mai, Cost of Staying -overall cost of your stay in Chiang Mai. 


\subsubsection{Procedure}

Data related to the overall satisfaction of tourists who visit Chiang Mai in 2013 is obtained from selfadministered questionnaires. Each category is measured by using a 5-point Likert scale ranging from one to five. 1 stands for very dissatisfied, 2 stands for dissatisfied, 3 stands for neutral, 4 stands for satisfied, and 5 stands for very satisfied. The collected data were analyzed using Statistical Package for Social Science (SPSS) version 6.0. Factor analysis was utilized to determine the underlying structure of the original 26 determinants toward tourist satisfaction. Lastly, multiple regression analysis was employed to investigate determinants, which affect the level of satisfaction of tourists in Chiang Mai. Multiple regressions is a statistical tool that enable us to determine how multiple independent variables are related to a dependent variable. In this research, 26 determinants are developed to identify the level of satisfaction of each determinant whereas overall satisfaction is referred to as dependent variable. Factor analysis is employed to reduce the dimensions of independent variables [9]. Significant factors affecting tourist satisfactions in Chiang Mai are identified using multiple regression analysis.

\section{Results}

\subsection{Descriptive Statistics}

The total number of respondents is 445 . However 309 of them are usable (69.44\%). Among the 309 respondents, there are 156 male and 153 female. In male respondents, there are $39(25 \%)$ who have visited Chiang Mai before. On the other hand, 117 (75\%) males have visited Chiang Mai for the first time. Out of 153 females, 32 (20.9\%) of them have visited Chiang Mai before, and the remaining 121 females have visited Chiang Mai for the first time. Therefore 71 tourists are repeat visitors. The majority of tourists, more than half of our samples, are from Europe.

\subsection{Factor Analysis and Multiple Regression}

The result of factor analysis is summarized in Table 3. Determinants (26) can be grouped into five factors: Hospitality, Attraction and Accessibility, Cost of Staying, Environmental Factor, and Infrastructure.

Table 3. Result of Factor Analysis

\begin{tabular}{|c|c|c|c|c|}
\hline Factor & Mean & $\begin{array}{c}\text { Std. } \\
\text { Deviation }\end{array}$ & $\begin{array}{c}\text { Factor } \\
\text { Loading }\end{array}$ & $\begin{array}{c}\text { Variance } \\
\text { Explained } \\
(\%)\end{array}$ \\
\hline FACTOR 1: Hospitality $\left(\mathrm{X}_{1}\right)$ & & & & 15.912 \\
\hline Appealing accommodation facilities & 4.20 & 0.738 & 0.458 & \\
\hline Variety of food and beverage & 4.31 & 0.740 & 0.784 & \\
\hline Quality of food and beverage & 4.27 & 0.697 & 0.748 & \\
\hline Willingness of staff to help tourists & 4.34 & 0.765 & 0.788 & \\
\hline Warm and welcoming of local people & 4.44 & 0.703 & 0.716 & \\
\hline FACTOR 2: Attraction \& Accessibility $\left(\mathrm{X}_{2}\right)$ & & & & 14.262 \\
\hline Variety of cultural attractions & 4.36 & 0.731 & 0.587 & \\
\hline
\end{tabular}


Variety of natural attractions

Local products

Availability of information and documents

Convenience to travel

Accessibility to basic medical treatment

Accessibility to local authorities

0.781

FACTOR 3: Cost of Staying $\left(\mathrm{X}_{3}\right)$

Price of accommodation

Price of food and beverages

Price of local transportation

Price of products

Overall cost of your stay in Chiang Mai

FACTOR 4: Environmental Factor $\left(\mathrm{X}_{4}\right)$

Quality of water supply

Availability of clean public toilets

Climate conditions

Air quality

Level of noise

Personal safety and security

Overall cleanliness

FACTOR 5: Infrastructure $\left(\mathrm{X}_{5}\right)$

Local transportation services

Availability of high speed internet and Wi-Fi

There are many assumptions for multiple regression analysis. However, some of the more frequently violated assumptions are reviewed here briefly. First, regression works best when there is a lack of multicollinearity, which is shown by the variance inflation factor (VIF). VIF should not exceed 10 [10]. Second, standard multiple regressions can only accurately estimate the relationship between dependent and independent variables if the relationships are linear in nature [11]. To determine the importance of each factor to tourist satisfaction in Chiang Mai, the multiple regression analysis was conducted based on earlier findings of the factor analysis. The overall tourist satisfaction was the dependent variable. All variables were entered at the same time. Referring to Table 4, the results of the multiple regression analysis indicates that all five factors significantly influence tourist satisfaction in Chiang Mai. Cost of staying turns out to be the most important factor, followed by Hospitality, Environment, Attraction and Accessibility, and Infrastructure in that order. 
Table 4. Regression Results: Factors Affecting Tourist Satisfaction in Chiang Mai

\begin{tabular}{|l|r|r|r|r|}
\hline \multicolumn{1}{|c|}{ Factor } & $\begin{array}{c}\text { Unstandardized } \\
\text { Coefficients }\end{array}$ & $\begin{array}{c}\text { Standardized } \\
\text { Coefficients }\end{array}$ & t-value & VIF \\
\hline Factor 1: Hospitality & 0.278 & 0.262 & $5.806^{* * *}$ & 1.710 \\
Factor 2: Attraction and Accessibility & 0.140 & 0.144 & $3.149^{* * *}$ & 1.743 \\
Factor 3: Cost of staying & 0.314 & 0.336 & $7.390^{* * *}$ & 1.730 \\
Factor 4: Environmental factor & 0.156 & 0.171 & $4.094^{* * *}$ & 1.464 \\
Factor 5: Infrastructure & 0.101 & 0.122 & $2.992^{* * *}$ & 1.394 \\
\hline Adjusted $R^{2}=0.633$ & & & \\
Durbin-Watson $=1.981$ & \multicolumn{3}{|l}{} \\
\hline
\end{tabular}

${ }^{*} \mathrm{p}<0.10,{ }^{* *} \mathrm{p}<0.05$, and ${ }^{* * *} \mathrm{p}<0.01$

The Durbin-Watson (DW) is always between 0 and 4 and the values of $1.5<\mathrm{DW}<2.5$ show that there is no auto-correlation in the data [12], and all VIF values in this study are less than 10. Furthermore, the normal P-Plot in this study is shown below in Figure 1 as the data are plotted against a theoretical normal distribution in a way that the points should form an approximate straight line. Departures from this straight line indicate departures from normality [13]. Data collected in this study indicate a relative normal distribution.

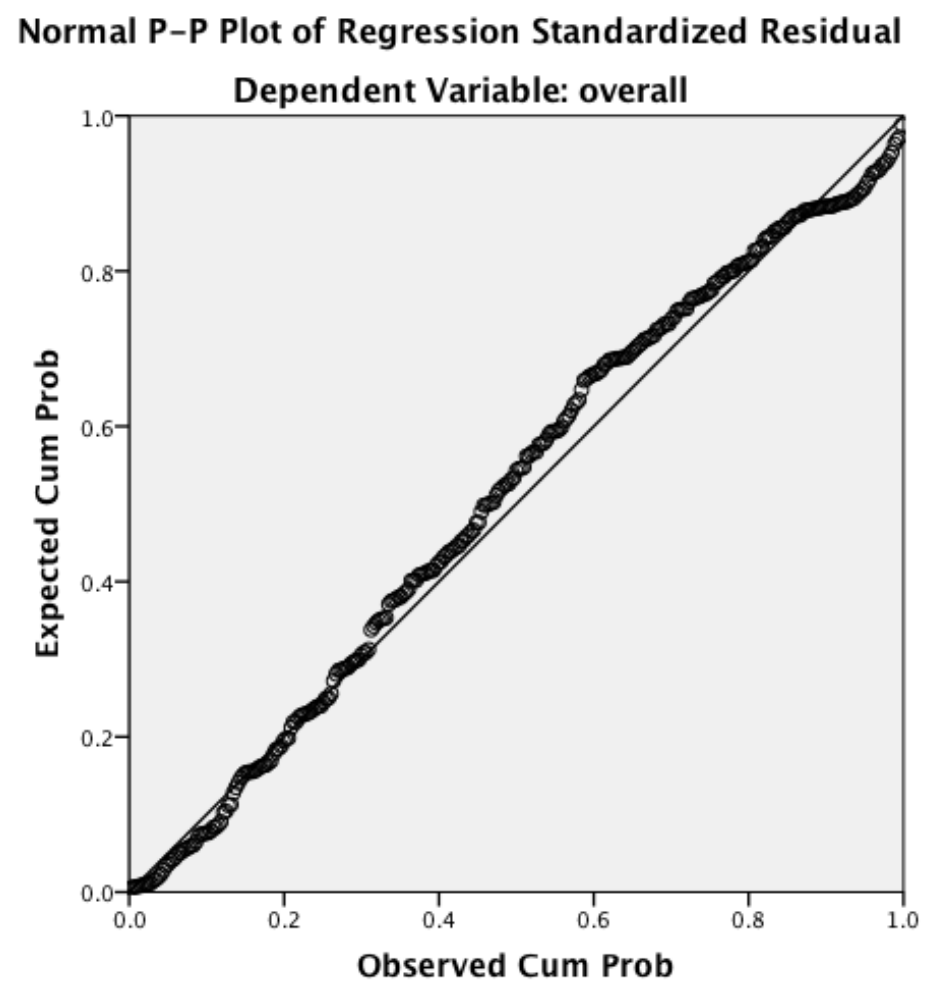

Figure 2. Normal P-Plot of Regression Standardized Residual Dependent Variable: Overall 


\section{Discussions}

Cost of Staying includes price of accommodation, food and beverage, transportation, products, and overall cost of stay. The cost of staying in Chiang Mai is fairly low, compared to similar attractions in other provinces. If the price of staying increases, the satisfaction of tourists will decrease. Hospitality is the second significant factor that affects tourist satisfaction. Thai people have friendly and welcoming characteristics and personality - known worldwide as the land of smiles. Tourists deeply witness and feel impressed by such matters of Thai culture. In addition, this inspires tourists to return to Chiang Mai in the future. Beyond the friendly and welcoming personality and instincts of Thai people, local food in Chiang Mai from small restaurants to luxury and decorative cuisines is unarguably unique and diverse. From the comment of surveys, one of the respondents said, "My favorite thing about Chiang Mai is the people. The people here are kind and helpful. I hope the people keep their warm and open hearts".

The environmental factors of Chiang Mai, geographically situated on highlands, create distinct and unique scenery for the eyes of tourists who are touched by what they have witnessed. The weather and climate in Chiang Mai is therefore pleasant to the people due to the geography of this province, making the place a perfect place for tourism all seasons round. As for tourists who love nature and natural attractions, Chiang Mai is an undeniably choice for such tourists.

Attraction and Accessibility of Chiang Mai has become a major factor that influences visitation of tourists in Chiang Mai. Chiang Mai, a heritage city which has existed for as long as seven centuries, has continued its rich and unique culture which is passed on from generations and is still maintained for the present. Most of the culture can be viewed from architecture such as temples and festivals. In addition, travelling to Chiang Mai is very easy because of the convenient transportation and travel routes to Chiang Mai due to international airports, which operates direct flights from aboard such as Seoul (South Korea), Singapore, China, Hong Kong, and Amsterdam (Netherlands). Domestically, diverse types of public transports are available from other provinces to Chiang Mai, for example, five trips by trains from Bangkok to Chiang Mai daily, and over 100 trips by public buses from Bangkok to Chiang Mai.

\section{Conclusion}

In conclusion, this study provides information that can be useful in the tourism industry to improve service quality in Chiang Mai. In preparation for the AEC, policies should be improved and developed to attract and satisfy tourists. Finally, this study indicates the most influential factor, which is Cost of Staying. The tourism authority of Thailand introduces new policies to prepare for the upcoming AEC. Those policies do not cover all factors, especially Cost of Staying, which should be the main concern for policy makers. All results obtained in this study is restrict to current information only. This study focuses only on factors that increase tourists' satisfaction.

This study can provide policy recommendations to government agencies. Controlling the standard of the price to be the same for both Thai and foreign tourists can raise the level of satisfaction among tourists. Besides this factor, conserving tourism resources (cultural and natural) and improving cleanliness of public toilets for both free and charge toilets can help in assisting the ability (of Chiang Mai) in the tourism industry to compete with other nations in the AEC. Methods of conserving tourism resources are: educating local people for the protection and judicious use of natural resources, stopping over utilization of natural resources, making habits for waste disposal, increasing the number of dustbin, and prohibiting heritage sites.

As suggested earlier, all policies recommended to government might not be doable because there are numerous limitations. For instance, competition within the private sector, amount of budget received from government are insufficient for development. There is also lack of consistency of developing government policy plan, and lack of short term and long- term planning. Furthermore, there is lack of implementation of policy in a systematical approach. Hence, government will have to play their role as supporters in terms of policies and fundamental infrastructure. This is to increase 
opportunities and abilities of the private sector to enhance the limitations of capabilities to compete in the tourism economy. Simultaneously, the private sector will have to cooperate and collaborate with government.

\section{Acknowledgement}

This research is partially supported by Sirindhorn International Institute of Technology. I would like to acknowledge Buddhapoom Maneechote, Paramee Chaisompongpun, Pawara Boonsorn, Paweena Jonngarmnent, and Tanattha Rakbamrung for their assistance in collecting the data.

\section{References}

1. C.A. Gunn, Tourism Planning, $2^{\text {nd }}$ Edition, New York, Taylor and Francis (1988)

2. Smith, S.L.J. The Tourism Product, Annals of Tourism research. http://ftur.uh.cu/intra/ftp/Materiales\%20docentes/4to\%20a\%F1o/Asignatura $\% 200$ cio/Tema $\% 20 I V$ /(\%20GOLF)/CD\%20\%20Golf\%20y\%20AAVV/Viajes\%20y\%20Productos/The\%20tourism\%20p roduct.pdf (1994)

3. V. Middleton, A. Fyall, M. Morgan, A. Ranchhod Marketing in Travel and Tourism, ButterworthHeinemann, Routledge; $4^{\text {th }}$ edition (2009)

4. R. D. Mason, Engineering Statistics for Business and Economics, $9^{\text {th }}$ Edition, Jakarta, Grants (2000)

5. Poerwanto, Geography of Tourism in Dictates Education, Ministry of Education and Culture, University of Jember (2000)

6. M. Kozak, M. Rimmington, Tourist satisfaction with Mallorca, Spain, as an off-season holiday destination, Journal of Travel Research 38, 260-269 (2000)

7. Pizam, Y. Neumann, A. Reichel, Dimensions of Tourist Satisfaction with a Destination, Annals of Tourism Research, 314-322 (1978)

8. Parasuraman, V.A. Zeithaml, L.L. Berry, A Conceptual Model of Service Quality and Its Implications for Future Research, Journal of Marketing 49, 41-50 (1985)

9. A.Crossman, Principle Components and Factor Analysis, http://sociology.about.com/b/2012/01/13/statistics-spotlight-principal-components-and-factoranalysis.htm, accessed December 23 (2013)

10. M. Kutner, C. Nachtsheim, and J. Neter Applied Linear Regression Models, $4^{\text {th }}$ Edition, New York, McGraw-Hill/Irwin (2004)

11. J.W. Osborne, E. Waters Four Assumptions of Multiple Regression That Researchers Should Always Test, North Carolina State University and University of Oklahoma Practical Assessment, Research, and Evaluation 8 (2002)

12. G.D. Garson, Testing Statistical Assumptions, Blue Book Series (2012)

13. J.M. Chambers, W.S. Cleveland, B. Kleiner, and P.A. Tukey, Graphical Methods for Data Analysis, Wadsworth International Group (1983) 